\author{
Military Technical College \\ Kobry El-Kobbah, \\ Cairo, Egypt.
}

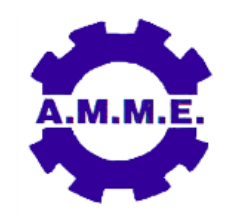
$17^{\text {th }}$ International Conference on Applied Mechanics and Mechanical Engineering.

\title{
HIGH-STRAIN SUPERPLASTICITY: CONCEPT, PROCESSING AND DEFORMATION MECHANISM
}

\author{
F. A. Mohamed*
}

\begin{abstract}
Micrograin Superplasticity refers to the ability of fine-grained materials $(1 \mu \mathrm{m}<\mathrm{d}<10$ $\mu \mathrm{m}$, where $\mathrm{d}$ is the grain size) to exhibit extensive neck-free elongations during deformation at elevated temperatures, which are equal to or greater than $500 \%$. There are two main advantages in utilizing superplastic materials for metal forming operations. First, large strains can be achieved without necking. Second, the stresses required for superplastic deformation are low. However, these large elongations associated with micrograin superplasticity are attained at strain rates in the range of $10^{-5}-10^{-3} \mathrm{~s}^{-1}$. Such a strain-rate range is slow for commercial forming of structural materials $\left(>10^{-2} \mathrm{~s}^{-1}\right.$ ). Recent advances in superplasticity have led to a new phenomenon known as high-strain rate (HSR) superplasticity that is very beneficial for commercial applications.
\end{abstract}

The present talk provides a brief review on: (a) the concept of HSR superplasticity, (b) processing techniques to achieve HSR superplasticity, (c) the characteristics of HSR superplasticity, (d) the deformation mechanism that controls HSR superplasticity, and (e) the lower bound for the grain size required to achieve HSR superplasticity.

* Department of Chemical Engineering and Material Science, Mechanical and Aerospace Engineering and Civil and Environmental Engineering, University of California, Irvine, California, 92697, USA. 